\title{
Adivinhação e espírito científico na Mesopotâmia
}

\author{
JEAN BOTTÉRO \\ École Pratique des Hautes Études, Paris
}

\begin{abstract}
RESUMO: Ler o futuro no figado dos animais pode favorecer o raciocínio empírico, a dedução e o espírito de sistema. Os antigos habitantes da Mesopotâmia provaramno ao inventar assim o espírito científico mais de 1000 anos antes de Cristo.
\end{abstract}

PALAVRAS-CHAVE: Mesopotâmia, adivinhação, ciência antiga, espirito científico.

No plano da história do pensamento científico, mais de uma vez se adiantou que uma ciência grega como a astronomia tem suas origens em uma prática divinatória mesopotâmica: a astrologia. Mas nunca se provou isso e talvez seja impossivel fazê-lo, tal o número de diferenças essenciais que há entre as duas. Pergunto-me se a questão assim formulada não foi mal colocada e se não se pode retomá-la de outra forma que dessa maneira retilínea e simplista. Eu gostaria de mostrá-lo discutindo - muito por alto, é evidente - as relações entre adivinhação e ciência na Mesopotâmia. Em outras palavras, sustentando que se comete um erro ao reservar a adivinhação à Mesopotâmia e a ciência à Grécia, mas que na Mesopotâmia mesmo, muito cedo e bem antes dos gregos, a adivinhação tornou-se um conhecimento de tipo científico e já, no essencial, uma ciência: o que pôde ser passado aos gregos foi de início e sobretudo essa visão científica, esse tratamento científico, esse espírito científico, de sorte que eles não construiram a partir de nada sua concepção da ciência, que nós herdamos, mas que nesse ponto capital, como em outros, eles são tributários dos velhos mesopotâmios.

\section{A adivinhação na Mesopotâmia}

Nesse pais são atestados dois tipos de adivinhação. Um, pela revelação dos deuses, a "adivinhação inspirada"; outro por uma atividade de um tipo de dedução: "a adivinhação dedutiva".

* Tradução de Filomena Yoshie Hirata Garcia, do original em francês "Divination et esprit scientifique", publicado em Sciences et Avenir 313, 1973, p. 284-9; republicado em BOTTÉRO, J. Mésopotamie. L'Écriture, la Raison et les Dieux. Paris: Gallimard, 1987, p. 157-69. 
A adivinhação inspirada é bem pouco conhecida e em áreas cronológica e localmente bem definidas. Ela não é típica da civilização mesopotâmica e não falaremos muito dela.

A adivinhação dedutiva, por outro lado, atestada sem interrupção desde os inícios do segundo milênio até a época selêucida, pouco antes de nossa era, deve ter sido o assunto de uma enorme massa de trabalhos e de documentos, se se julgar a quantidade considerável que nos restou dela: sem contar as peças inumeráveis da prática, nós encontramos mais de trinta mil oráculos, divididos em uma centena de "tratados" no mínimo. É sem dúvida a atividade mental, ao mesmo tempo, melhor conhecida e mais característica da cultura mesopotâmica.

Essa mina gigantesca não parece ter sido explorada na sua medida pelos assiriólogos. Há entre eles, hoje, poucos especialistas de textos divinatórios e a maior parte parecem ser talmudistas. Uma das razões desse desfavor é talvez de início a extraordinária monotomia aparente dos tratados de adivinhação que constituem as principais peças do dossiê. Mas eu me pergunto se a principal não é que, conscientemente ou não, se considera a mântica em tudo e por tudo uma simples superstição: frívola, antiquada e que não merece verdadeiramente tantos esforços.

Uma tal maneira de ver implica uma atitude digamos "egocêntrica", particularmente perniciosa em História. A própria vocação do historiador não é somente, através dos testemunhos que nos restam, encontrar o passado, mas encontrá-lo tal qual ele era, nele mesmo, isto é, vendo-o, sentindo-o, julgando-o, não do nosso ponto de vista, mas como o viam, o julgavam e o viviam seus atores. Se um historiador tem verdadeiramente o sentido de seu oficio, deve então sempre esforçar-se para sair de si mesmo e de seu tempo para colocar-se no lugar e no tempo das personagens cujos fatos e obras ele estuda. Considerar, mesmo subconscientemente, a adivinhação mesopotâmica uma superstição, é julgá-la em relação a nós: é portanto se proibir de algum dia entendê-la, é faltar a uma das regras essenciais de nossa disciplina. Tentemos pois contemplar e julgar essa mântica, colocando-nos, tanto quanto possivel, na ótica de seus velhos usuários e familiares. Reter-nos-á aqui, naturalmente, a adivinhação dedutiva como atividade intelectual, como tipo de conhecimento.

\section{Como se apresentam os textos divinatórios}

Os documentos essenciais, os mais originais e os mais típicos são os que podem ser chamados "tratados". Eles se apresentam como coleções mais ou menos amplas (às vezes muitos milhares) de oráculos que são todos tirados, no mesmo tratado, do mesmo objeto material considerado nas suas apresentações particulares ou anormais: por exemplo, tais ou tais posições de tal astro, ou ainda, tais aspectos mais ou menos monstruosos de um recém-nascido.

Se se faz a conta desses objetos cujas figuras eram reputadas ominosas - para 
utilizar esse sinônimo latinizante de "divinatório" - e enumeradas nos "tratados", percebe-se que eles recobrem o universo material quase inteiro: os astros e os meteoros; o tempo e o calendário; a configuração das terras, dos cursos d'água, das aglomerações; a apresentação dos elementos inanimados e dos vegetais; o nascimento e a conformação dos animais; e seu comportamento; e sobretudo o próprio homem: seu aspecto físico, sua conduta, sua maneira de viver, sua vida consciente e onírica... Além desses fenômenos que se apresentavam naturalmente à observação, outros estavam latentes, e era preciso revelar: como a anatomia interna dos animais sacrificados; ou virtuais, que se devia provocar: como a forma tomada pelo óleo ou pela farinha lançados na água. Certamente, não se poderia dizer que esses múltiplos objetos ominosos tenham tido em toda parte e sempre o mesmo interesse aos olhos dos praticantes da adivinhação: mas o que conta, aqui, é que todos tenham podido ser considerados como objetos possíveis do exame e da dedução divinatórios, que o universo material inteiro, em suma, tenha sido tomado por uma matéria cujo estudo atento podia, de alguma forma, extrair o futuro. Havia aí e é o primeiro traço a observar, uma curiosidade enciclopédica já muito marcante.

Os elementos irredutiveis desses "tratados", do ponto de vista estilístico e lógico, são os "oráculos", dos quais cada um detalha e explica uma apresentação ominosa do objeto do tratado e disso deduz o que ela deixa prever do futuro. Todo, do primeiro ao último, são exatamente construidos sobre o mesmo esquema gramatical e lógico: um primeiro membro da frase, uma "prótase" como dizem os gramáticos, seguido de um segundo: uma "apódose". A prótase, introduzida (ao menos virtualmente) pela marca da hipótese: "Se", "Suposto que" (em acádio, shoumma), fornece o detalhe da apresentação do objeto: é o presságio. A apódose expõe a parte de futuro que se deduz do presságio: é o prognóstico. Por exemplo: "Se um homem tem o pêlo do tórax enrolado para cima: ele cairá na escravidão"; "Se um homem, com o rosto congestionado, tem seu olho direito proeminente: longe de sua casa, cães o devorarão"; "Se a vesícula biliar [do carneiro sacrificado] é desprovida de canal colédoco: o exército do rei, durante uma expedição militar, sofrerá de sede"; "Se o Vento do Norte varre a face do céu até o aparecimento da Lua Nova: a colheita será abundante".

\section{Sentido e gênese da adivinhação dedutiva}

Para quem procura compreender essa adivinhação como atividade intelectual, como modo de conhecimento, o que há de mais importante é bem menos a prótase ou a apódose que a passagem da primeira à segunda: como se explica que do fato de um homem ter o pêlo do tórax em cachos voltados para o alto, se possa sentir-se fundamentado para concluir que ele cairá na escravidão?

Para responder a essa questão fundamental, seria preciso compreender como nasceu a adivinhação dedutiva na Mesopotâmia. Não sabemos o bastante senão para fazer 
conjecturas, ao menos, com essa alta probabilidade feita de dados convergentes, com a qual é preciso freqüentemente que nos contentemos, quando fazemos a história de um mundo tão antigo e extinto.

A adivinhação parece bem ter sido de início puramente empírica; isto é, fundada sobre a simples constatação e a posteriori. O que nos permite pensá-lo e, ao mesmo instante, nos esclarece sobre esse estádio original, é um certo número de oráculos disseminados na enorme coleção que nos resta e que se chamaram "históricos" porque seu prognóstico, em lugar de ser no futuro, é no passado e se refere a um acontecimento antigo da história do país reputado dever se reproduzir. Por exemplo: "Se, na parte direita do figado [do cordeiro sacrificado] se encontram duas excrescências-digitiformes [provavelmente o que os anatomistas chamam processus pyramidal]: é o presságio do tempo de anarquia [em outros termos, o período entre 2198 e 2195 mais ou menos, que precedeu de uns trinta anos a queda da Dinastia de Accad]". E ainda: "Se, no figado, a parte dita 'Porta do Palácio' [a 'incisão umbilical' dos anatomistas, parece] é dupla, que há três rins e que à direita da vesícula biliar estão furadas [em acádio: palshou] três perfurações [em acádio: pilshou] bem marcadas: é o presságio do povo de Apishal [uma cidade do extremo norte ou noroeste do pais], que o rei Narâm-Sin [quarto da dinastia Accad; cerca de 2260 - 2223] fez prisioneiro recorrendo a sapas [em acádio: pilshou]". Uma outra formulação que se encontra entre os mais antigos documentos formalmente ligados à adivinhação dedutiva, as célebres "maquetas de figados" encontradas em Mari, é talvez ainda mais eloqüente: "Quando meu país se levantou contra Ibbî-Sîn [último rei da $3^{\text {a }}$ Dinastia de Ur; cerca de 2027 - 2023]: é assim que o figado se encontrava disposto". (Notar-se-á que as maquetas em questão não datam de mais de cerca de meio século após essa revolta) Isso sublinha o elo estreito observado entre a disposição particular do figado de uma vítima sacrificada um belo dia e a revolta contra o último rei de Ur III. É preciso de resto levar em conta que quase todos os episódios registrados nos oráculos históricos são do meio milênio, entre a época de Accad e os primeiros tempos do $2^{\circ}$ milênio, e nós temos boas razões para conjecturar que foi esse justamente o período em que se desenvolveu, amadureceu e se fixou a adivinhação dedutiva no país.

Esses acontecimentos assim registrados pelos oráculos históricos, por mais que nós os conheçamos por outras vias, têm grande chance de ser autênticos: visto sua data muito aproximada, o último exemplo citado acima, o da maqueta de Mari, é particularmente impressionante nesse ponto. De um outro lado, como não há, com toda evidência, o menor elo intrínseco ou necessário entre cada um deles e o aspecto do presságio com o qual ele é posto assim em relação, é preciso que esses oráculos tenham sido fundados sobre a constatação da coincidência dos dois fenômenos.

Nesse pais que, nós sabemos, há muito tempo se interessou pelo que os romanos chamavam portenta - acontecimentos fora do comum que deixam pressagiar alguma coisa, sacrificadores, dissecando uma de suas vítimas, terão observado que seu figado se apresentava de forma inusitada e, pouco tempo após, ter-se-á produzido um aconte- 
cimento notável, uma "virada" na história do rei ou do país. A coincidência terá sido de início percebida, depois sublinhada, depois, talvez, graças a outras da mesma espécie, multiplicadas aos olhos de pessoas que "nelas acreditavam" e que a esperavam ela terá sido julgada outra coisa que um encontro de acaso - post hoc, ergo proptes hoc - o primeiro fenômeno terá sido tomado para o anúncio do segundo e os dois juntos registrados como um oráculo de valor universal, de sorte que se pudesse, cada vez que se encontrasse em seguida a mesma anomalia, esperar ver se reproduzir um acidente análogo no destino do país ou do soberano.

Essas conclusões não devem certamente ser reservadas apenas aos oráculos históricos propriamente ditos. Muitos outros, quer digam respeito ao país, ao rei, ou a simples indivíduos, parecem ter devido sua origem a constatações análogas: a única diferença é que não se julgou necessário conservar ai menção dos nomes próprios ou das circunstâncias individualizadas preservadas nos oráculos históricos. Prognósticos como: "Presságio da neve que recobre o país (inteiro)" ou "Presságio da retirada, (a saber) quando o exército bate em retirada", guardam na sua apresentação mesma a marca dos oráculos históricos. Mas muitos outros, que não a guardam, particularmente abundantes nos mais velhos tratados, mas que se encontram ainda, fossilizados aqui e lá nas épocas as mais recentes, conservaram muitos traços singulares, para que aí se pudesse discernir, facilmente, um acontecimento concreto determinado ou como uma anedota, um fait divers, tirados do dia-a-dia. Eis alguns exemplos, entre milhares: "Um leão, após ter matado alguém diante da Grande Porta da Cidade, será abatido, por sua vez"; "Um menino cairá de um teto"; "A cidade que tu terás ido saquear, quando tu te encontrares face a ela, sua guanição cortará as barricadas endireitadas para investi-la e fará uma saida contra ti"; e enfim essa pérola: "A esposa desse homem, grávida das obras de um outro, não cessará de implorar à deusa Ishtar e de dizer olhando seu esposo: contanto que eu faça meu filho à semelhança de meu marido!"...

O mais velho conteúdo de oráculos tem, portanto, todas as chances de ter sido constituído dessa forma: por verificação de seqüências de acontecimentos que não tinham entre si nenhum elo aparente, mas, observou-se, tinham-se sucedido uma vez e estabeleceu-se de imediato que eles se sucederiam sempre. É o que nós chamamos empirismo.

Parece que, muito cedo talvez, tenha-se desejado ir mais longe procurando, além das aparências, um elo inteiro entre os dois acontecimentos que constituiam um oráculo. Retomemos, olhando-os de mais perto, os primeiros prognósticos relatados acima. Em um, as duas excrescências digitiformes evocam a rivalidade dos competidores ao trono, que preenche o "Tempo da anarquia". No segundo, às perfurações (pilshou) furadas (palshou) no figado respondem, nos prognósticos, não somente as sapas (pilshou) que servem para forçar a cidade saqueada, mas, com uma ligeira metátese (e nós temos, na literatura acádia, outros exemplos dessas aproximações fonéticas), o nome mesmo dessa cidade: Apishal. A nossos olhos, tais "elos" não são elos: são puras coincidências sem envergadura. É preciso crer (nós o sabemos de resto por outras vias) que não era assim para os velhos mesopotâmios, sobretudo com sua doutrina, bem 
conhecida dos assiriólogos, do governo do mundo pelos deuses e, nesse objetivo, da fixação prévia dos destinos de todas as coisas por esses mesmos deuses. Nesse país, onde, desde os primeiros tempos do $3^{\circ}$ milênio, foi inventada a escrita e onde ela gozou um papel capital na vida material e intelectual, imaginava-se que as sortes assim decididas estavam inscritas pelos deuses sobre o "Tablete dos destinos". Os deuses podiam mesmo escrever essas decisões nas coisas, à medida que eles as criavam ou dirigiam seu movimento. Um certo número de textos falam nesse sentido, como esse: "Ó deus Shamash[...] tu que inscreves o oráculo e marcas a sentença divinatória nas entranhas do cordeiro!" - e mesmo se, no estado em que nós os encontramos, eles são do $1^{\circ}$ milênio, deveriam testemunhar uma tradição bem mais arcaica. Por sua vez, a natureza mesma, original e inata, da escritura cuneiforme, queria que ela tivesse sido de início e que tivesse permanecido sempre mais ou menos uma escrita das coisas: pelos pictogramas que são em suma coisas para designar outras - o croquis do pé para o "andar", ou o estar em pé; a figura do triângulo pubiano para a "mulher", a "feminilidade". Dai podia vir a idéia de que inscritas pelos deuses sobre o figado das vitimas as duas excrescências digitiformes, em lugar de uma só esperada, marcavam sem dúvida a dualidade, a oposição, o conflito e assim representavam, nessa "escrita divina", o papel de pictograma da rivalidade, da competição, como as "perfurações" traduziam as "sapas".

Dessa maneira de ver saiu, portanto, como uma regra, não formulada, mas sempre aplicada, calcada sobre aquela que presidia à escrita: por toda parte em que no presságio figurava o mesmo signo, se "leria" o mesmo acontecimento futuro. De fato, por toda parte em que se encontra na descrição do objeto oracular uma dualidade (anormal, inesperada; pois isso que é corrente, habitual e segundo a regra não retém a atenção e não é portanto por si ominoso), tem-se no prognóstico uma idéia de oposição, de rivalidade, de desacordo, de luta...

Poder-se-iam acumular exemplos sem número para mostrar a que ponto a adivinhação, na Mesopotâmia, funcionava verdadeiramente como a escrita: por decifração dos "pictogramas". Há evidentemente numerosos casos, na adivinhação de resto como na escrita, onde a relação entre o significante e o significado não é mais nem límpido, nem mesmo às vezes inteligivel, ou imaginável. Para nós. Mas não seguramente para os velhos mesopotâmios e isso é que é importante.

Foi assim que a adivinhação passou do estágio primitivo de simples constatação empírica àquele de conhecimento a priori, de conhecimento dedutivo. A partir do momento em que se descobriu que o leão é o signo, o ideograma da violência ou da preponderância, tornava-se inútil "esperar os acontecimentos", como isso teria sido indispensável em regime empírico; podia-se prever infalivelmente brutalidade, matança ou dominação por pouco que se tivesse registrado, num contexto ominoso, a presença de um leão. Eis uma transformação capital e de uma importância considerável: pois que, de fato, um conhecimento a priori, um conhecimento dedutivo é já, no essencial, uma ciência. 


\section{A ciência divinatória e a colocação em "tratados"}

Um tal caráter "científico" explica numerosos traços que se destacam desde os mais velhos tratados.

Notadamente, essa vontade de análise e ao mesmo tempo de sistemática que chocam tanto o leitor dos tratados. Em cada um deles, o objeto oracular é decomposto em um número às vezes surpreendente de apresentações ominosas: por exemplo, a configuração do crânio do homem, e em particular de sua cabeleira, não conta menos de 166 parágrafos no "tratado" de fisiognomonia. E essa decomposição e essa classificação se fazem em boa regra segundo um certo número de categorias recorrentes: a presença do objeto ou sua ausência; suas quantidades e suas dimensões; sua disposição interna e sua posição relativa; sua coloração, levada às vezes a uma dezena de matrizes em torno das cores principais, que eram então o vermelho, o branco, o preto e o verde-amarelo; depois a adição ou a falta de elementos adventícios; e assim por diante. $\mathrm{E}$ todas essas eventualidades estão enfileiradas numa ordem bastante rigorosa e constante.

É bem evidente que, ao menos num certo número de casos, todas essas hipóteses não puderam ser realmente constatadas; há mesmo algumas que são impossíveis. Assim, no figado das vítimas estão previstas duas vesículas biliares: fenômeno raro (e é por isso que ele é ominoso), mas ainda imaginável; em seguida, levado por sua vontade de sistemática, o autor do tratado coloca três, cinco e até sete cifras totalmente fantásticas. Igualmente, após menção de gêmeos que a mulher põe no mundo, pretende-se triplos, quádruplos, quíntuplos, depois sêxtuplos, óctuplos e enfim nônuplos!

Nessa sistematização que, repudiando todo empirismo, todo apelo à experiência, toda referência ou real controlado, chega-se a eventualidades totalmente impossíveis, há no fim das contas uma vontade de registrar, não só tudo que foi observado, mas também tudo aquilo que teoricamente deveria ser observado, tudo aquilo que, sem jamais ter sido, poderia ser. E de fato, para quem não tinha nossas evidências biológicas, por que um fígado que tem duas vesículas biliares não poderia ter mais e até sete? O caráter científico da adivinhação levou-a, portanto, além do real, até o possível: em outras palavras, em termos de lógica, a adivinhação mesopotâmica procurou estudar seu objeto como universal e, de certa maneira, in abstracto, o que é igualmente um dos traços próprios do conhecimento científico.

Foi porque ela assim se tornou e, sem dúvida, desde o fim do $2^{\circ}$ milênio, uma ciência verdadeira, que se sentiu a necessidade de colocar a adivinhação em "tratados". Os "tratados" - e a definição vale para outras disciplinas atualizadas pelos velhos mesopotâmios: a jurisprudência, a medicina, e também, à sua maneira, a matemática - eram os "manuais" de uma ciência, que eles procuravam colocar ao alcance daqueles que deviam aprendê-la. Eles não o faziam como nós, destacando e anunciando princípios e leis: é notório que os mesopotâmios de outrora jamais formularam tais 
abstrações em direção a que a forma de seus espíritos não os levava: não existe mesmo em seu vocabulário o menor termo para designar "princípios" ou "leis" em não importa que ordem de idéias. Em conformidade com seu tipo de inteligência, eles dispensavam muito bem tais enunciados universais e abstratos na sua forma: preferiam casos concretos e individualizados que acumulavam e faziam variar para sugerir assim, por esse viés, a idéia geral.

Os "tratados" são manuais de casuística: fazendo o desvio dos dados variáveis de um mesmo objeto, quer eles fossem reais ou imaginários, constatados ou postos a prio$r i$, aquele que os assimilava adquiria o sentido das leis e dos princípios, sem ter necessidade de ler cada palavra de forma abstrata. Em nenhum lugar se dizia que o leão anunciava a tirania, a matança, a violência, o poder supremo: mas por força de encontrar casos onde à presença de um leão na prótase, em contextos diversos, respondia no prognóstico, aqui o império, aqui o massacre, aqui a força brutal, o leitor se deixou penetrar por essa lei sem nunca tê-la formulado. Foi assim que nos ensinaram, quando éramos crianças e o nosso espírito não teria compreendido o enunciado abstrato de um princípio qualquer, a aritmética e a gramática, fazendo-nos aprender de cor tábuas de adição, de subtração, de multiplicação e de paradigmas nominais e verbais, as quais são listas de casos variáveis como os tratados mesopotâmicos. A existência de tais tratados sublinha, portanto, ainda o caráter científico da adivinhação.

\section{A "invenção" do espirito científico}

De um conhecimento de pura constatação, a posteriori, tratando de casos individuais, contingentes e não-previsíveis, a adivinhação tomou-se assim, antes mesmo da época de nossos mais velhos tratados, isto é, pelo fim do $3^{\circ}$ milênio ao menos, um conhecimento a priori, dedutivo, sistemático, capaz de prever, tendo um objeto necessário, universal, e, a sua maneira, abstrato, e possuindo mesmo seus "manuais".

Eis aí o que nós chamamos uma ciência, no sentido próprio e formal do termo, tal qual nos inculcaram nossos velhos mestres gregos, após Platão e Aristóteles, e tal qual comanda ainda no essencial a nossa própria idéia moderna de ciência - para aqueles dentre nós, ao menos, que guardam seu espírito suficientemente aberto e desperto para não reservar esse termo às únicas disciplinas de tipo matemático, como se o universo não fosse maior que os números e as quantidades...

Nessa ciência divinatória, é preciso distinguir com cuidado o objeto e o método, ou o espírito.

O objeto: o futuro contingente cognoscivel através do presente, dedutível do presente, não podia guardar qualquer consistência senão numa mentalidade como a dos antigos mesopotâmios, aos olhos dos quais o mundo era conduzido por potências superiores, as quais, decidindo segundo sua vontade sua sorte futura, conheciam disso o detalhe e podiam então notificá-lo e o notificavam com efeito "inscrevendo-o" nas 
coisas. Um tal objeto perdia todo crédito numa visão diferente do universo. Também os gregos - falo aqui dos filósofos e sábios - o repudiaram, e com mais razão nós mesmos o consideramos vazio de todo sentido, fora de moda e "supersticioso".

Mas o método, o espírito, uma vez atualizados, não dependiam de seu objeto primeiro e guardavam seu valor uma vez esse último anulado: essa curiosidade enciclopédica, essa maneira de abordar o real universal procurando um conhecimento analítico, necessário, dedutivo, a priori: essa atitude abstrata e científica diante das coisas era uma aquisição definitiva do espírito humano, um enriquecimento e um progresso consideráveis, e que não se podia mais esquecer como o fogo ou a escrita uma vez descobertos. Não tenho que lembrar aqui como os gregos conheceram e assimilaram esse espírito científico, nascido antes deles e fora do limite deles: procuro somente a origem e vejo que ele apareceu, ao menos na Mesopotâmia, mais de quinze séculos antes de Sócrates, Platão e Aristóteles, e mesmo que seu nascimento e sua atualização não sejam observados em nenhum lugar melhor que nessa adivinhação que constitui um dos traços essenciais e típicos da civilização mesopotâmica antiga.

Aí está, é preciso convir, um momento capital da história do homem. Tanto quanto a invenção do jogo, da cultura das plantas, da domesticação dos animais, da metalurgia e da escrita, a da abstração e do conhecimento universal e racional, em uma palavra, daquilo que chamamos o Espirito científico, representa, ao menos julgado do nosso ponto de vista, isto é, em relação ao que nós nos tornamos e ao que nos faz sempre viver, um progresso admirável.

Não justifica ele, por si só, a própria existência dos assiriólogos e todos seus esforços?

BOTTÉRO, J. Divination et sprit scientifique en Mésopotamie. Clássica, São Paulo, 4: 25-34, 1991.

RÉSUMÉ: Lire l'avenir dans le foie des animaux peut favoriser le raisonnement empirique, la déduction et l'esprit de système. Les anciens habitants de la Mésopotamie l'ont prouvé en inventant ainsi l'esprit scientifique plus de 1000 ans avant les Grecs. MOTS CLÉs: Mésopotamie, divination, science antique, esprit scientifique. 
J. Bottéro: Adivinhação e

espirito científico na Mesopotâmia

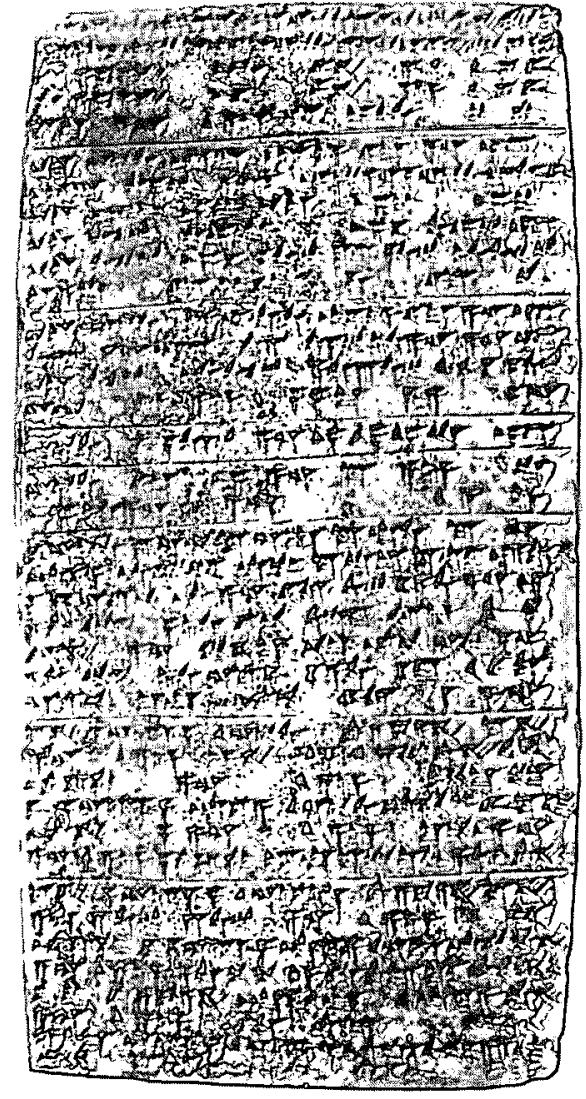

Tablete de argila com inscrição cuneiforme mencionando presságios tirados da observação dos planetas e referindo-se à chuva e à enchente. Uruk (sul da Mesopotâmia, atual Iraque), $25 \times 13,2 \mathrm{~cm}$, séc. II a.C. Museu do Louvre, Ao 6449. Foto: Museu do Louvre.

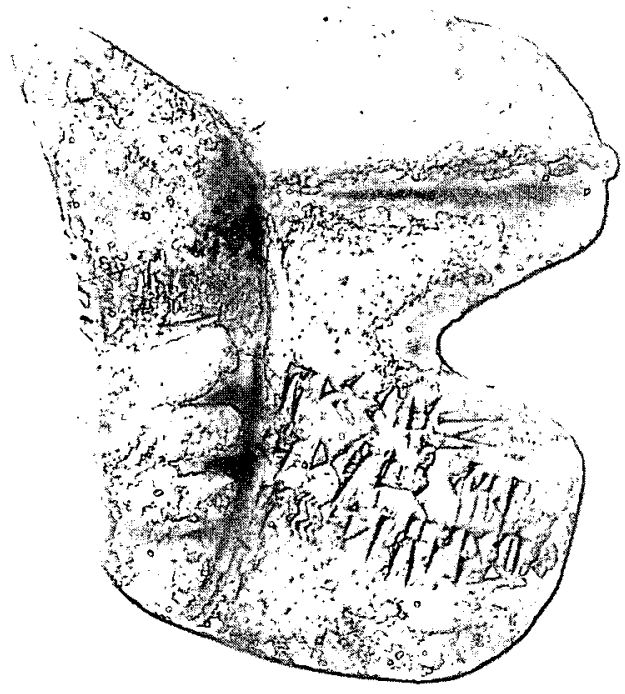

Maqueta de figado de animal, de argila, com texto divinatório referente à destruição de pequenas cidades. Palácio de Mari (Síria), 6,6 X 5,9 cn, séc. XIX a.C. Museu do Louvre, Ao 19837. Foto: Museu do Louvre. 